\title{
Molecular Genetics at the Fort Collins Science Center
}

The mission of the U.S. Geological Survey (USGS) at the Fort Collins Science Center Molecular Ecology Laboratory is to use the tools and concepts of molecular genetics to address a variety of complex management questions and conservation issues facing the management of the Nation's fish and wildlife resources.

Together with our partners, we design and implement studies to document genetic diversity and the distribution of genetic variation among individuals, populations, and species. Information from these studies is used to support wildlifemanagement planning and conservation actions. Current and past studies have provided information to assess taxonomic boundaries, inform listing decisions made under the Endangered Species Act, identify unique or genetically depauperate populations, estimate population size or survival rates, develop management or recovery plans, breed wildlife in captivity, relocate wildlife from one location to another, and assess the effects of environmental change.

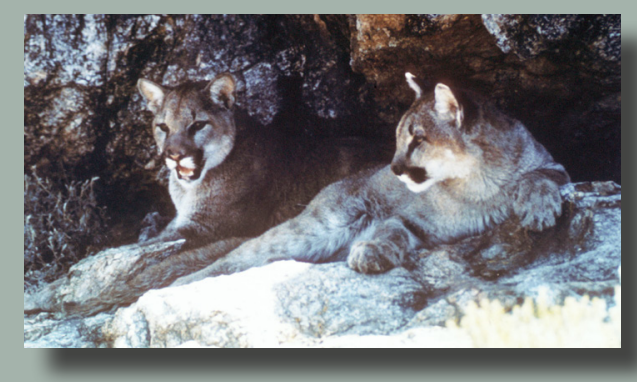

\section{Applying the Science of Molecular Genetics to the Issues of Biological Conservation}

The use of molecular genetics has become increasingly important in the fields of wildlife biology, conservation biology, restoration ecology, and ecosystem science. Genetic diversity, the amount of genetic variability within a species, is an important aspect of biological diversity and plays an essential role in the conservation of species and ecosystem diversity. At the species level, conservation of genetic variability is important to the overall health of populations because such variation can represent adaptive responses to different types of environments present within a species' range. Such variation may play an important role in surviving novel diseases and adapting to environmental changes associated with anthropogenic (influenced by humans) stressors, such as climate change or habitat loss. Furthermore, because different species coexist in communities, the loss of genetic diversity in one species can affect the structure and composition of the community of species within an ecosystem, which in turn may have a cascading effect on ecosystem health, integrity, and sustainability.

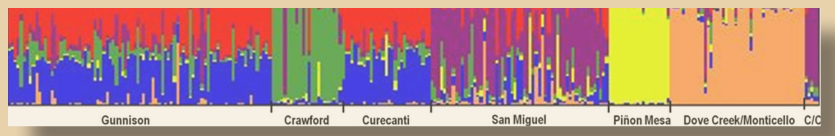

\section{Real World Applications}

Recent advances in molecular biology allow us to develop and apply the tools and concepts of molecular genetics to the conservation of biological resources. In many cases, single or multiple genes are selected for understanding the status and dynamics of wildlife populations. Working with our partners, we design and implement studies that provide the genetic information needed to address the issues and problems described in the following paragraphs.

Population structure - Genetic data can be used to determine the level of genetic variation within and between populations and, consequently, the level of gene flow and movement among populations throughout a species' range.

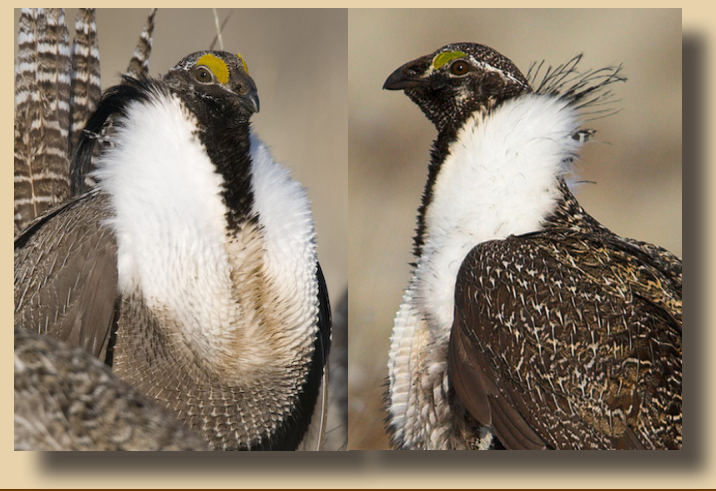

Assess taxonomic uncertainty - Genetic data, along with other lines of evidence, such as morphological and behavioral characteristics, can be used to identify and potentially to redefine the existing taxonomic classification of a given species or subspecies. Such delineations are highly relevant for species status determinations (endangered, threatened, or at-risk).

Delineation of discrete populations - Genetic data can be particularly relevant in identifying and differentiating discrete populations that may warrant special protection (Distinct Population Segment) or specific management strategies (management unit). 


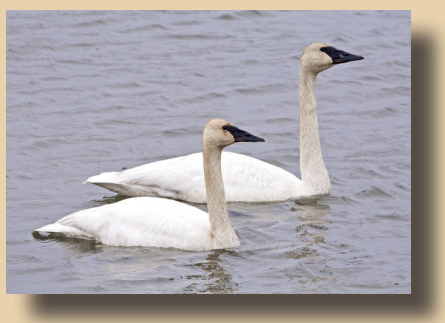

Assess environmental change - With advancing genomic technology, it is now possible to locate and to assess genes that may be directly involved in a species' ability to respond to environmental change (for example, climate change).

Landscape genetics - Genetic data can be used in conjunction with landscape data (for example, habitat, elevation, roads) to identify landscape features that function as barriers to movement for species.

Assess family relations/mating system - Genetic data can be used to investigate mating systems and parentage, and evaluate how these data may influence effective population size, the number of individuals in a population that actually contributes genes to succeeding generations.

Population modeling - Genetic data can be used in population models for predicting the potential effects of different management scenarios (for example, fertility control) on genetic diversity of managed populations.

Captive breeding and reintroduction/translocations - Genetic data can be used to inform captive breeding, reintroduction, and translocation programs to ensure that genetic diversity is maximized, or to ensure that when moving animals from one location to another, the genetic makeup of the individual or the population is considered.

Estimate population size and survival rates - DNA from non-invasively sampled individuals (using feathers, feces, or hair, for example) can be used as a molecular tag and analyzed with traditional mark-recapture techniques to estimate population size and survival rates.

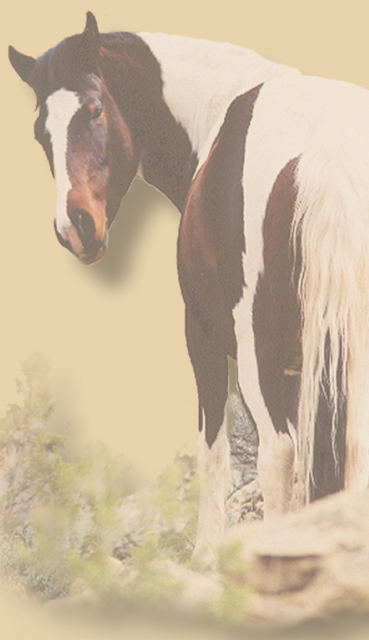

Gender identification - Genetic data can be used to identify the gender of an individual when morphological or behavioral characteristics between males and females are indistinguishable.

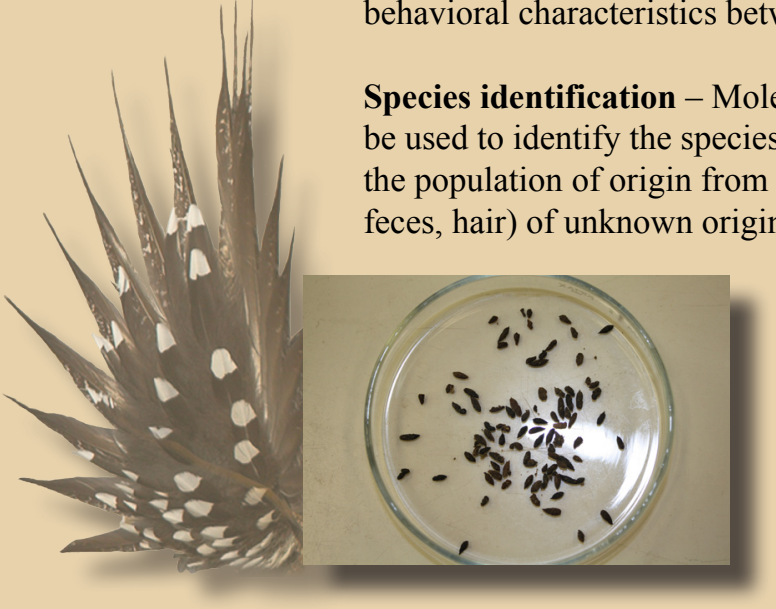

Species identification - Molecular genetics tests can be used to identify the species and somtimes even the population of origin from a sample (feather, tissue,

\section{For Further Information}

For inquiries about science capabilities, research, services, or partnership opportunities, please see our website http://www.fort.usgs.gov/MEL/ or contact:

\section{Principal Investigator \\ Sara Oyler-McCance \\ Research Geneticist \\ Phone: $970-226-9197$ \\ Email: soyler@usgs.gov \\ Laboratory Address: \\ Fort Collins Science Center 2150 Centre Avenue, Bldg C \\ Fort Collins, CO 80526-8118}

\author{
Laboratory Manager \\ Jennifer Fike \\ Geneticist \\ Phone: 970-226-9199 \\ Email: fikej@usgs.gov
}

For further information on genetics research and capabilities within the U.S. Geological Survey, visit the USGS Genetics and Genomics website at http://ecosystems.usgs.gov/genetics_genomics/

Photos: Front page, American Black Bear (Waverley Traylor, U.S. Fish and Wildlife Service), Greater Sage-grouse (Stephen Ting, U.S. Fish and Wildlife Service), Broad-tailed Hummingbird (Bill Ratcliff), Lynx (Erwin and Peggy Bauer, U.S. Fish and Wildlife Service), Mountain Lions (U. S. Fish and Wildlife Service), Gunnison Sage-grouse (Gerrit Vyn), Greate Sage-grouse (Stephen Ting, U. S. Fish and Wildlife Service); Back page, Trumpeter Swans (Donna Dewhurst, U.S. Fish and Wildlife Service), Wild Horse (Marty Felix), Greater Sagegrouse tail feathers (Stephen Ting, U.S. Fish and Wildlife Service), Bat guano in petri dish (Ernie Valdez), Indiana Bat (Susi von Oettingen), Molecular Ecology Laboratory (Dean Biggins), Midget Faded Rattlesnake (Josh Parker). 